\title{
Stabbing headache as the initial manifestation of herpetic meningoencephalitis
}

\author{
Luis Fabiano Marin - Andre Carvalho Felício - William Adolfo Celso Santos • \\ Paulo Cesar Floriano Silva · Jean Carlo Gorinchteyn · Ivan Silva Marinho
}

Received: 27 March 2010/Accepted: 22 April 2010/Published online: 9 May 2010

(C) Springer-Verlag 2010

Dear Editor,

Stabbing headache $(\mathrm{SH})$ is a short-lasting and painful headache that may happen as a primary headache, develop concurrent with other headache types, or may be associated with several conditions [1-3]. We describe a case of a woman who developed a $\mathrm{SH}$ as the first manifestation of herpes zoster (HZ) meningoencephalitis.

A 79-year-old woman was admitted to the emergency department with a 1 day history of stabbing pain paroxysms in the right temporal and frontal regions lasting a few seconds (the duration of each stab was between 1 and $3 \mathrm{~s}$ ). The stabs of pain started suddenly and were repetitive and very intense. Physical examination revealed itchy red macules, papules and vesicles on her right chest. Neurological examination showed spatial and temporal disorientation and neck stiffness, without altered consciousness or focal neurological signs. The cerebral spinal fluid (CSF) analysis revealed 106 leukocytes $/ \mathrm{mm}^{3}$ (62\% lymphocytes), protein: $63 \mathrm{mg} / \mathrm{dL}$ and glucose $52 \mathrm{mg} / \mathrm{dL}$. Endovenous acyclovir treatment was promptly initiated $(10 \mathrm{mg} / \mathrm{kg} / 8$ hourly). Brain magnetic resonance imaging and electroencephalogram were normal. Varicella zoster virus IgG by enzymelinked immunosorbent assay test in the CSF was positive. After 2 days of acyclovir treatment, the stabs of pain

L. F. Marin $(\bowtie)$ - A. C. Felício · W. A. C. Santos

Department of Neurology, Hospital e Maternidade São Camilo

Pompeia, Maranhão st., 500/30, São Paulo, SP 01240-000, Brazil

e-mail: luisfabianom@gmail.com

P. C. F. Silva - J. C. Gorinchteyn - I. S. Marinho Department of Infectious Diseases, Hospital e Maternidade São Camilo Pompeia, São Paulo, SP, Brazil completely disappeared and 60 days after symptoms onset, the patient remained asymptomatic.

To our knowledge, this is the first case reporting $\mathrm{SH}$ as the initial symptom of HZ meningoencephalitis, alongside with headache improvement after intravenous acyclovir. In previous studies, the authors were able only to report the association with $\mathrm{HZ}$, but no direct relationship between $\mathrm{SH}$ and $\mathrm{HZ}$ meningoencephalitis [3].

Headache is one of the most frequent symptoms of $\mathrm{HZ}$ meningoencephalitis, usually characterized by severe pain $[4,5]$. In our case, the headache characteristics were compatible with SH [1] that ameliorated with acyclovir, reinforcing its relationship with an infectious agent. Interestingly, another report showed a patient with herpes simplex encephalitis presenting with a migraine-like headache, which also improved after acyclovir therapy [6].

This case shows the importance of careful evaluation for underlying causes of $\mathrm{SH}$, demonstrating that this uncommon type of headache may be the initial symptom of $\mathrm{HZ}$ meningoencephalitis, a potentially life-threatening disease without early recognition and prompt treatment.

Conflict of interest None.

\section{References}

1. Pareja JA, Ruiz J, de Isla C, al-Sabbab H, Espejo J (1996) Idiopathic stabbing headache (jabs and jolts syndrome). Cephalalgia 16:93-96

2. Raieli V, Eliseo GL, Vecchia ML, Franca GL, Pandolfi E, Puma D, Ragusa D, Eliseo M (2002) Idiopathic stabbing headache in the juvenile population: a clinical study and review of the literature. J Headache Pain 3:21-25

3. Pascual J (2009) Other primary headaches. Neurol Clin 27:557571 
4. Gilden D (2004) Varicella zoster virus and central nervous system syndromes. Herpes 11:89A-94A

5. Braun-Falco M, Hoffmann M (2009) Herpes zoster with progression to acute varicella zoster virus-meningoencephalitis. Int $\mathrm{J}$ Dermatol 48:834-839
6. Peters EW, de Bruijn SF (2005) Migraine treated with acyclovir. Headache 45:396-397 